\title{
A compact triband microstrip antenna utilizing hexagonal CSRR for wireless communication systems
}

\author{
Murtala Aminu-Baba ${ }^{1}$, Mohamad Kamal A. Rahim² ${ }^{2}$ Farid Zubir ${ }^{3}$, Mohd Fairus Mohd Yusoff ${ }^{4}$, \\ Adamu Y Iliyasu', Mohammed Mustapha Gajibo ${ }^{6}$, Huda A. Majid ${ }^{7}$, K. I Jahun ${ }^{8}$ \\ 1,2,3,4,5,6 Advanced RF \& Microwave Research Group, School of Electrical Engineering, Faculty of Engineering, \\ Universiti Teknologi Malaysia, Malaysia \\ ${ }^{7}$ Faculty of Engineering Technology (FTK), Department of Electrical Engineering Technology, \\ Universiti Tun Hussein Onn Malaysia, Malaysia \\ ${ }^{1,8}$ Department of Computer and Communication Engineering, Faculty of Engineering and Engineering Technology, \\ Abubakar Tafawa Balewa University, Nigeria.
}

\section{Article Info}

Article history:

Received Jan 3, 2020

Revised Mar 7, 2020

Accepted Apr 9, 2020

\section{Keywords:}

$4 \mathrm{G}$

CSRR

Miniaturization

Patch antenna

Triband

\begin{abstract}
In this paper, a compact triband printed antenna with hexagonal complementary split-ring resonators (CSRRs) for 4G applications is proposed. The proposed multiband antenna is comprised of a rectangular patch antenna on the top plane, while on the ground plane, hexagonal CSRRs are etched for size miniaturization (at the lower bands) and multiband generation. Another effect of the CSRR is the shifting of the initial resonance of the patch antenna from $5.17 \mathrm{GHz}$ to the higher band of $6.18 \mathrm{GHz}$. The triband of $180 \mathrm{MHz}, 2.4 \sim 2.59,150 \mathrm{MHz}, 2.79 \sim 2.94$ and $420 \mathrm{MHz}$ 6.04 6.46 $\mathrm{GHz}$ bands acquired can cover WLAN/Wi-Fi and WiMAX operating bands adequately. This can be achieved by choosing the optimal size and position of the CSRR on the ground plane carefully. The design occupies a total size of $45 \times 45 \mathrm{~mm}^{2}$ using the low-cost FR-4 substrate. Good agreements are obtained between the measured results and the simulated, which are discussed and presented.
\end{abstract}

This is an open access article under the CC BY-SA license.

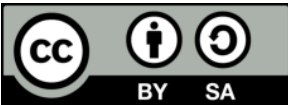

\section{Corresponding Author:}

Murtala Aminu-Baba,

Advanced RF \& Microwave Research Group, School of Electrical Engineering,

Faculty of Engineering, Universiti Teknologi Malaysia, UTM,

81310 Skudai, Johor Bahru, Malaysia.

Email: limaminkobi@yahoo.com

\section{INTRODUCTION}

In recent years, the demand for multiband antennas has attracted great attention due to their advantages of supporting several communication standards, which can be incorporated in mobile wireless devices. The benefits of having such type of antenna are; first, it satisfies the requirement of multiband operation by operating at the most widely used bands, GSM, WLAN, WiMAX, or combination of them. Secondly, the antenna encourages the portability of contemporary mobile communication systems [1-3]. Microstrip patch antenna has been a suitable candidate in the communication systems due to its low cost, low profile, and simplicity in the design and fabrication. Various types of patch antennas appropriate for WLAN applications have been reported [4-11].

Different methods have been used to achieve multiband function such as metamaterial structure [8, 12-16], slots [17-20], and Defected Ground Structure (DGS) [21-25] to mention but a few. In $[4,8]$, a patch antenna was adopted with square, hexagonal, and circular CSRR on the ground plane, 
respectively. The authors achieved both WiMAX and WLAN at the lower and upper-frequency bands, but the design did not cover the $6 \mathrm{GHz}$. Similar procedures using metamaterial structures were proposed in $[5,6]$. However, all the designs are limited to lower frequency bands of $5 \mathrm{GHz}$. In another method [7], a number of $\mathrm{U}$ shapes were etched for multiband use and antenna miniaturization with metalized vias. As part of their contribution, stable directional radiation patterns were realized, which have a compact size. However, by introducing additional components in the antenna, more difficulty and cost are added. In [10], a hexagonal CSRRs was etched on the ground plane of a patch antenna attached with extra radiating elements, which results in realizing a multiband antenna.

Similarly, in [14], multiple hexagonal CSRRs are loaded for miniaturization and multiband realization on a hexagonal monopole antenna. The prototype covers the most commonly used frequency bands of GPS, WLAN, and WiMAX that are appropriate for the lower frequencies. The two concepts in the literature reported achieved a low compact multiband antenna size. Moreover, with the introduction of additional radiating branches on the antenna element has more complexity while this branch has little gain.

In this paper, hexagonal CSRR on the ground plane is used to achieve size miniaturization and multiband function for WLAN and WiMAX applications. Similarly, the integration of the CSRR and the patch antenna enhances the performance of the antenna without the CSRR by shifting the initial resonance frequency of the patch antenna from $5.17 \mathrm{GHz}$ to $6.18 \mathrm{GHz}$. At the lower frequencies of 2.45 and $2.86 \mathrm{GHz}$, the CSRR acts as the radiating element. This has given a size reduction of $79 \%$ for the WLAN frequency band.

\section{DESIGN CONSIDERATION}

Figure 1 shows the antenna geometry and structure employed in the process of design and development for the triple-band metamaterial antenna. The structure was designed using an FR-4 substrate with a thickness of $1.6 \mathrm{~mm}$, relative permittivity of 4.4 , and a loss tangent of 0.02 . The overall dimension of the antenna covers $45 \times 45 \mathrm{~mm}^{2}$. The width of the microstrip feeding line is $2.93 \mathrm{~mm}$ and has a gap distance of $0.6 \mathrm{~mm}$ between the feedline and the patch antenna. This corresponds to the characteristics input impedance of $50 \Omega$. The numerical analysis and appropriate geometrical parameters needed in the proposed design were carried out using computer simulation technology (CST) software.

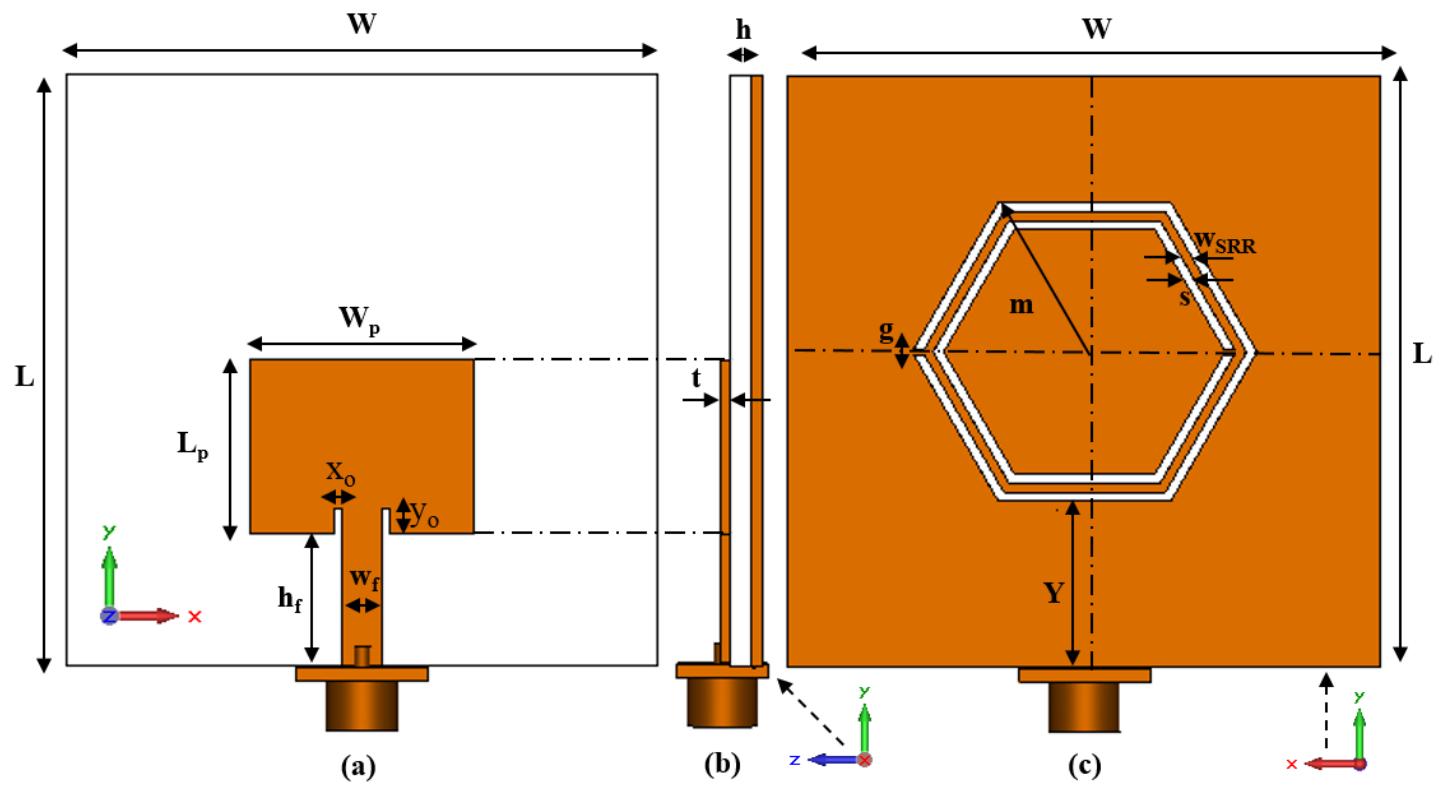

Figure 1. The geometry of proposed patch antenna with hexagonal CSRR, (a) Top view, (b) Side view, and (c) Bottom view

\subsection{Parametric study}

Multiple parameters affect antenna performance. Thus, the influence of most important parameters, including the CSRR size $m$, and positions of the CSRR $Y$ in the ground plane, are therefore simulated and displayed in Figure 2. The frequencies can be regulated to the desired frequency of interest by adjusting 
the CSRR size, which shifts from the higher band to the lower frequency, as shown in Figure 2(a). Therefore, the bigger the size of the CSRR, the lower the frequency, and vice versa. Secondly, the effect of CSRR position on the ground plane has a great influence on the frequencies, as indicated in Figure 2(b). By varying the CSRR position from the lower level of the ground plane to the higher level, thus, transforming the undesired frequency to more suitable ones.

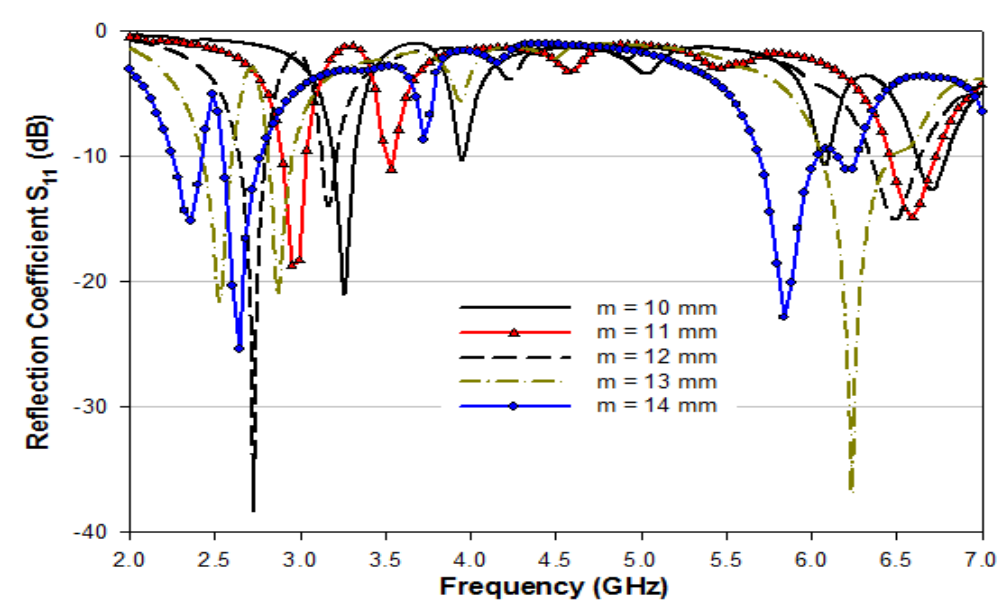

(a)

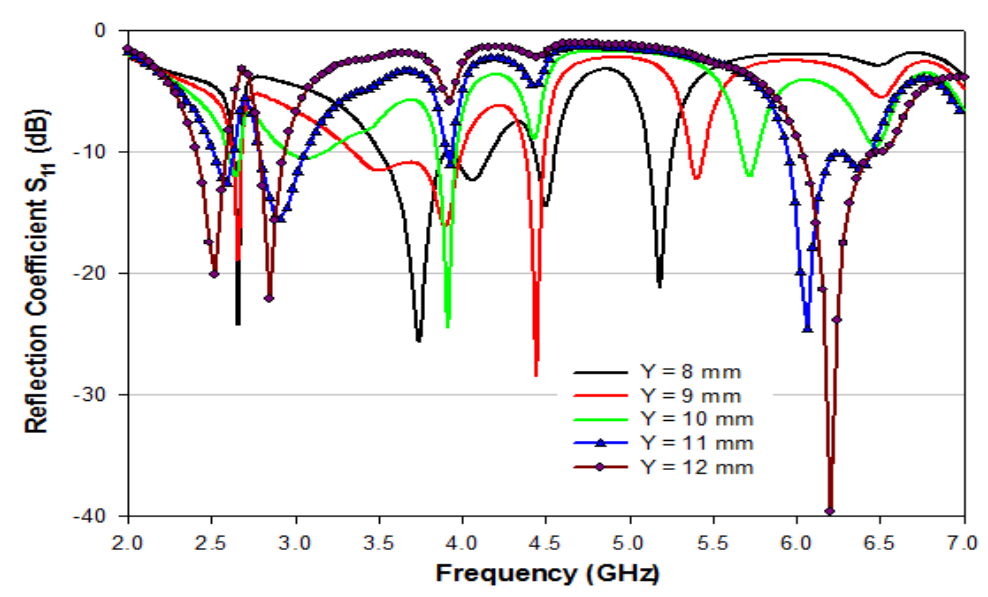

(b)

Figure 2. Effect of parameters on the patch antenna design (a) Varying parameter $m$ (b) Varying parameter $Y$

From the parametric studies, the optimum values of the CSRR size and positions of the return loss are selected, as shown in Table 1. The simulated design was fabricated and tested for validation and further analysis. Details of the fabrication and measurement processes are discussed in section 3. Table 1 shows the dimensions of the optimized parameters for the proposed antenna.

Table 1 Dimensions of the antenna design

\begin{tabular}{cccc}
\hline Parameters & Dimensions $(\mathrm{mm})$ & Parameters & Dimensions $(\mathrm{mm})$ \\
\hline $\mathrm{L}$ & 45.00 & $\mathrm{~g}$ & 0.40 \\
$\mathrm{~W}$ & 45.00 & $\mathrm{~h}_{\mathrm{f}}$ & 10.00 \\
$\mathrm{~W}_{\mathrm{p}}$ & 17.10 & $\mathrm{~W}_{\mathrm{f}}$ & 2.93 \\
$\mathrm{~L}_{\mathrm{p}}$ & 13.30 & $\mathrm{~s}$ & 0.80 \\
$\mathrm{x}_{0}$ & 0.60 & $\mathrm{~m}$ & 13.0 \\
$\mathrm{y}_{0}$ & 2.00 & $\mathrm{t}$ & 0.035 \\
$\mathrm{~h}$ & 1.60 & $\mathrm{w}_{\mathrm{SRR}}$ & 0.80 \\
$\mathrm{Y}$ & 12.00 & & \\
\hline
\end{tabular}




\section{MEASUREMENT, RESULTS, AND ANALYSIS}

The prototype of the proposed patch antenna with hexagonal CSRR is fabricated and measured using the specifications described in the previous section. Figure 3 shows the photograph of the fabricated antenna, while Figure 4 depicts the simulated and measured reflection coefficients against the frequency of the proposed antenna. The antenna prototype is fabricated, tested, and analyzed. Similarly, the performances of the proposed antenna in terms of the reflection coefficient, $S_{11}$, and bandwidth are measured by the Rohde \& Schwarz ZVL network analyzer. Also, the far-field tests were carried in an anechoic in the ARFMG Lab, UTM. It can be observed that the simulated and measured return loss present good reasonable agreements, as shown in Figure 4. However, the differences in some of the simulated and measured results are likely due of the tolerance in fabrication or connector losses.

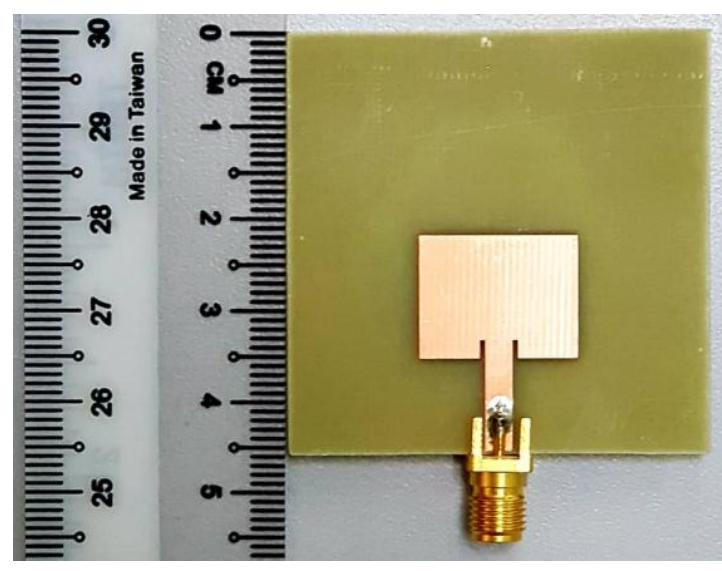

(a)

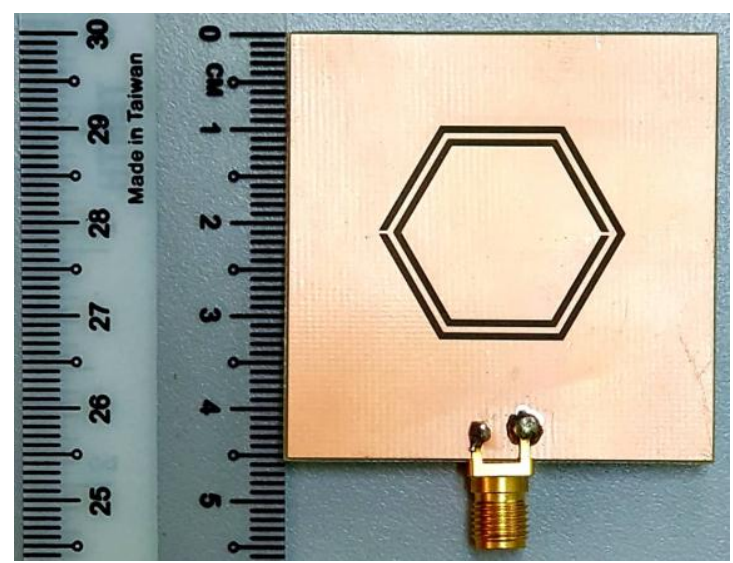

(b)

Figure 3. Photograph of the fabricated proposed patch antenna with Hexagonal CSRR, (a) Top plane, (b) Bottom plane

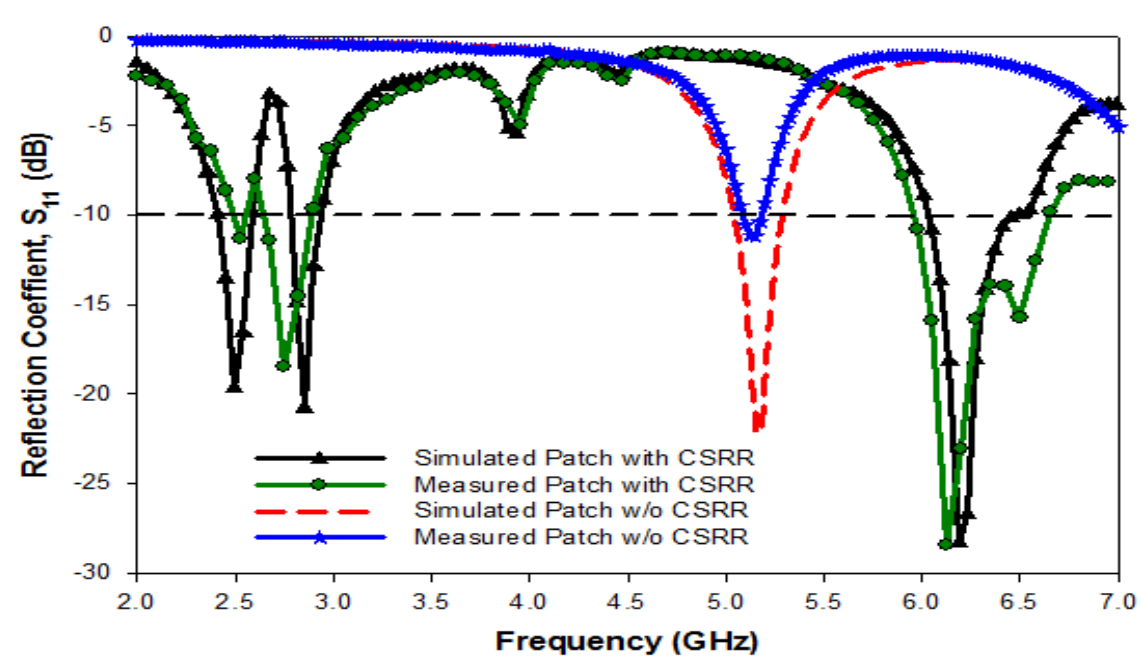

Figure 4. The simulated and measured reflection coefficient of patch antenna with and without hexagonal CSRR

\subsection{Simulated surface currents}

Figure 5 shows the simulated surface current distribution of the patch antenna with hexagonal CSRR at $2.45,2.86$, and $6.19 \mathrm{GHz}$, respectively. It is seen at the $2.45 \mathrm{GHz}$ that the surface current flows through the microstrip feed line and is more concentrated at the left and right sides of the hexagonal rings. Similarly, the second frequency exhibits a similar current flow but with additional concentration on the antenna radiating element. 
In the higher frequency, $6.18 \mathrm{GHz}$, the current distribution flows more through the inset feed and the rectangular patch. Little concentration is noticed on the CSRR and the top plane of the substrate. The shift of the initial resonant frequency from $5.17 \mathrm{GHz}$ to $6.18 \mathrm{GHz}$ may be attributed to the effect of the radiation from the CSRR, even though it creates two additional bands at the lower frequency

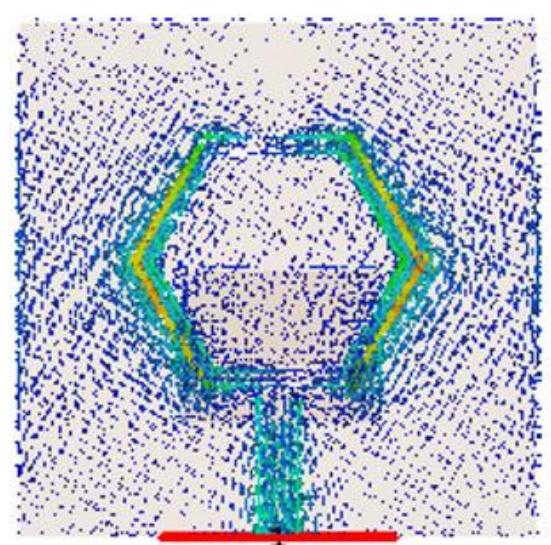

(a)
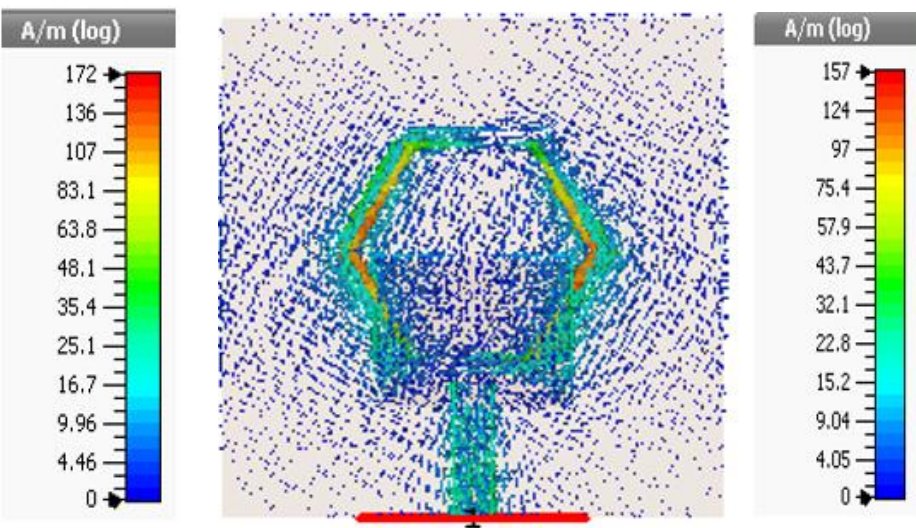

(b)

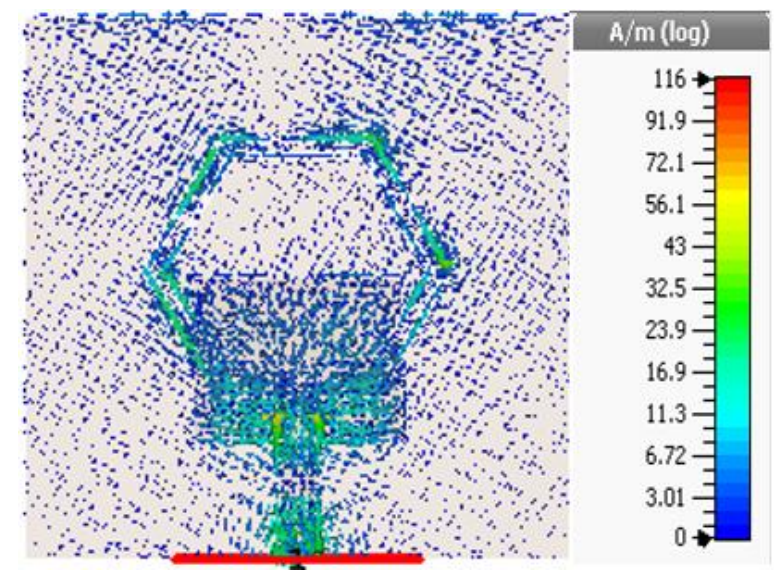

(c)

Figure 5. Simulated Surface current distribution, (a) $2.45 \mathrm{GHz}$, (b) 2.86 , (c) $6.18 \mathrm{GHz}$

\subsection{Radiation patterns}

The normalized simulated and measured radiation patterns in the $\mathrm{E}$ and $\mathrm{H}$ planes are displayed in Figure 6, respectively. The proposed patch antenna with hexagonal CSRR is characterized by 8-shaped bidirectional radiation patterns at the lower frequencies in the E-plane, and omnidirectional pattern in all frequencies in the H-plane. However, the E-plane radiation pattern in the higher band frequency; $6.11 \mathrm{GHz}$ exhibits bidirectional, and its shape becomes quite omnidirectional with the increase in frequency. Table 2 shows the summary performance of the proposed multiband antenna. The bandwidths and gains corresponding to the frequencies are presented and discussed

Table 2 Performance summary of the proposed antenna

\begin{tabular}{cccc}
\hline \multicolumn{4}{c}{ Microstrip Antenna with Hexagonal CSRR } \\
\hline Frequency GHz & 2.45 & 2.86 & 6.186 \\
& $(2.41 \sim 2.59)$ & $(2.79 \sim 2.94)$ & $(6.04 \sim 6.46)$ \\
Bandwidth & $180 \mathrm{MHz}$ & $150 \mathrm{MHz}$ & $420 \mathrm{MHz}$ \\
& 1.76 & 2.33 & 3.16 \\
Gain (dB) & 74.99 & 65.12 & 66.39 \\
Efficiency \% &
\end{tabular}




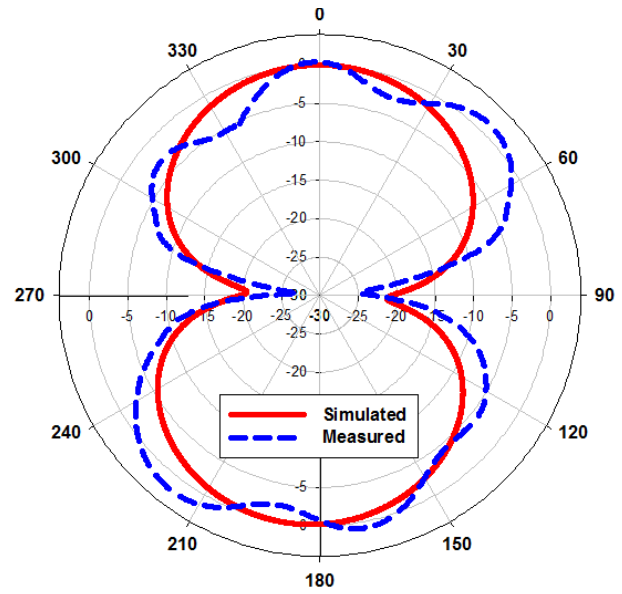

(a)

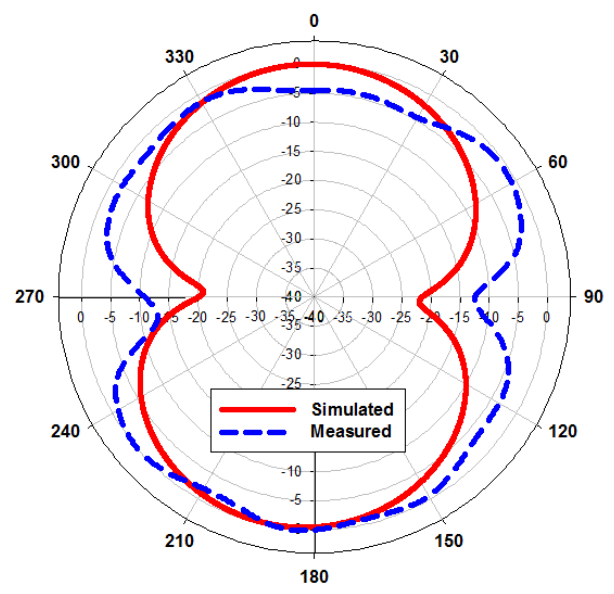

(c)

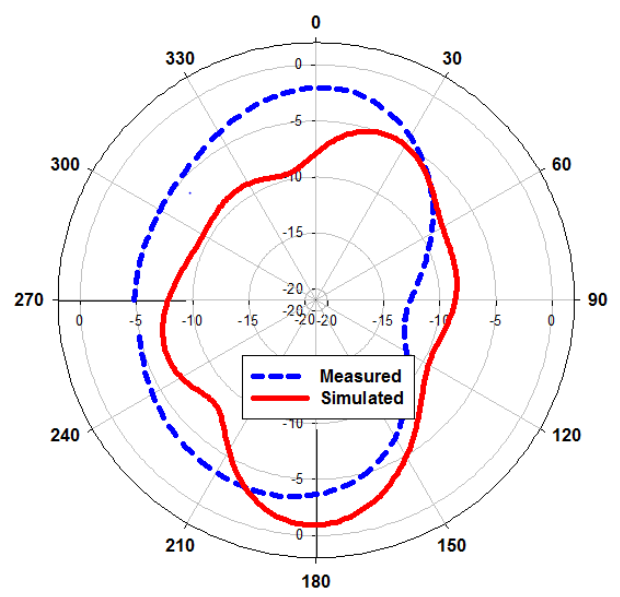

(e)

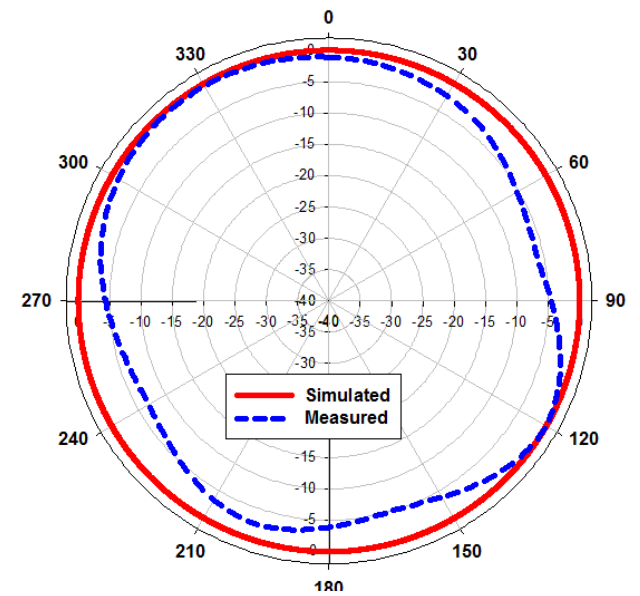

(b)

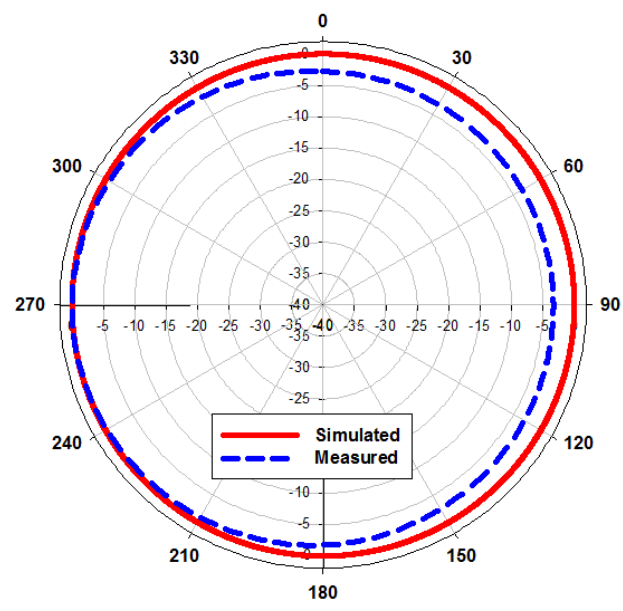

(d)

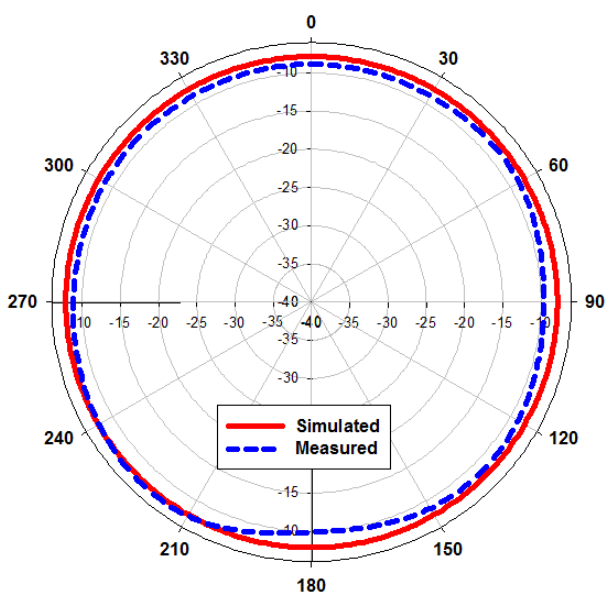

(f)

Figure 6. Simulated and measured radiations patterns of the proposed patch antenna with hexagonal CSRR, (a) E-plane 2.45, (b) H-plane 2.45, (c) E-plane 2.86, (d) H-plane 2.86, (e) E-plane 6.18 GHz, (f) H-plane $6.18 \mathrm{GHz}$ 


\section{CONCLUSION}

A compact triband patch antenna with hexagonal CSRR for WLAN and WiMAX applications is proposed. The design is validated by fabrication and measurements. The lower frequency bands were achieved through the etching of the hexagonal CSRR on the ground plane. Details of the parametric studies for the fundamental parameters of the triband antenna is presented. Good agreement between the measured results and the simulated was realized, as shown in the plots. The discrepancies in the comparisons might be attributed to the fabrication loss, SMA port mismatch, testing cable, etc. The proposed antenna has demonstrated good performance in the radiation patterns, gain, impedance bandwidths, and compact size. The proposed multiband antenna is therefore suited for WLAN and WiMAX applications through this distinctive characteristic.

\section{ACKNOWLEDGMENTS}

The authors would like to thank the Ministry of Education (MOE) for supporting the research work, Research Management Center (RMC), School of Postgraduate (SPS), School of Electrical Engineering and Universiti Teknologi Malaysia (UTM) Johor Bahru for the support of the research under grant no 04 G67 and 06G15. The author would also like to acknowledge all members of Advanced Microwave and Antenna Lab (AMAL) P18 FKE-UTM

\section{REFERENCES}

[1] M. Naser-Moghadasi, R. Sadeghzadeh, L. Asadpor and B. S. Virdee, "A Small Dual-Band CPW-Fed Monopole Antenna for GSM and WLAN Applications," in IEEE Antennas and Wireless Propagation Letters, vol. 12, pp. 508-511, 2013.

[2] A. Y. Iliyasu, M. R. Bin Hamid, M. K. A. Rahim, M. Aminu-Baba and M. F. Bin Mohd, "Frequency Reconfigurable Wideband Metamaterial Antenna Design with CSRR," 2019 IEEE Conference on Antenna Measurements \& Applications (CAMA), Kuta, Bali, Indonesia, pp. 1-4, 2019.

[3] M. Aminu-Baba et al., "Planar Monopole Antenna With Hexagonal Split Ring Resonators," 2018 IEEE AsiaPacific Conference on Antennas and Propagation (APCAP), Auckland, pp. 1-2, 2018.

[4] M. Aminu-Baba, M. K. A. Rahim, F. Zubir, M. F. M. Yusoff and A. Bello Shallah, "Microstrip antenna with CSRR ground structure," 2017 International Symposium on Antennas and Propagation (ISAP), Phuket, pp. 1-2, 2017.

[5] K. Li, C. Zhu, L. Li, Y. Cai and C. Liang, "Design of Electrically Small Metamaterial Antenna With ELC and EBG Loading," in IEEE Antennas and Wireless Propagation Letters, vol. 12, pp. 678-681, 2013.

[6] Md. Mehedi Hasan, Mohammad Rashed Iqbal Faruque, Mohammad Tariqul Islam, "Thin-Layer Dielectric and Left-Handed Metamaterial Stacked Compact Triband Antenna for $2 \mathrm{GHz}$ to $4 \mathrm{GHz}$ Wireless Networks," Journal of Electronic Materials, vol. 48, no. 6, pp. 3979-3990, 2019.

[7] A. Boukarkar, X. Q. Lin, Y. Jiang and Y. Q. Yu, "Miniaturized Single-Feed Multiband Patch Antennas," in IEEE Transactions on Antennas and Propagation, vol. 65, no. 2, pp. 850-854, Feb. 2017.

[8] M. Aminu-Baba, M. K. A. Rahim, F. Zubir, and M. F. M. Yusoff, "Design of Miniaturized Multiband Patch Antenna Using CSRR for WLAN/WiMaX Applications," TELKOMNIKA Telecommunication, Computing, Electronics and Control, vol. 16, no. 4, pp. 1838-1845, 2018.

[9] M. M. Tirkey, A. K. Tiwary, "A Compact Dual-Band Antenna Using Hexagonal Complementary Split Ring Resonator," Microwave Review, vol. 24, no. 2, pp. 19-25, 2018.

[10] S. I. Rosaline, S. Raghavan, "CSRR- Based Compact Penta Band Printed Antenna for GPS/GSM/WLAN/Wimax Applications," Microwave and Optical Technology Letters, vol. 57, no. 7, pp. 1538-1542, 2015.

[11] B. Murugeshwari, R. S. Daniel, S. Raghavan, "A Compact Dual Band Antenna Based on Metamaterial-Inspired Split Ring Structure and Hexagonal Complementary Split-Ring Resonator for ISM/Wimax/WLAN Applications," Applied Physics A, vol. 125, no. 628, 2019.

[12] R. Hussain, M. U. Khan, E. Almajali and M. S. Sharawi, "Split-ring-resonator-loaded multiband frequency agile slot-based MIMO antenna system," in IET Microwaves, Antennas \& Propagation, vol. 13, no. 14, pp. 2449-2456, 2019.

[13] M. Aminu-Baba, M. K. A. Rahim, F. Zubir, M. F. M. Yusoff, and N. A. Samsuri, "Wideband Monopole Antenna with Rotational Circular SRR," 10th International Conference on Robotics, Vision, Signal Processing and Power Applications, Springer, Singapore, pp. 419-424, 2019.

[14] R. S. Daniel, R. Pandeeswari, S. Raghavan, "A Miniaturized Printed Monopole Antenna Loaded with Hexagonal Complementary Split Ring Resonators for Multiband Operations," International Journal of RF and Microwave Computer-Aided Engineering, vol. 28, no. 7, 2018.

[15] M. S. Sharawi, M. U. Khan, A. B. Numan and D. N. Aloi, "A CSRR Loaded MIMO Antenna System for ISM Band Operation," in IEEE Transactions on Antennas and Propagation, vol. 61, no. 8, pp. 4265-4274, Aug. 2013.

[16] C. Arora, S. S. Pattnaik, R. Baral, "Dual Band Microstrip Patch Antenna Array Loaded with Split Ring Resonators and Via Holes," AEU-International Journal of Electronics and Communications, vol. 93, pp. 253-260, 2018.

[17] M. Shalini, M. Ganesh Madhan, "Performance predictions of slotted graphene patch antenna for multiband operation in terahertz regime," Optik, vol. 204, February 2020. 
[18] H. Ahmad, W. Zaman, S. Bashir, M. Rahman, "Compact Triband Slotted Printed Monopole Antenna for WLAN and WiMaX Applications," International Journal of RF and Microwave Computer-Aided Engineering, vol. 30, no. $1,2020$.

[19] G. Liu, Y. Liu, S. Gong, "Compact Tri- Band Wide- Slot Monopole Antenna with Dual- Ring Resonator for WLAN/WiMAX Applications," Microwave and Optical Technology Letters, vol. 58, no. 5, pp. 1097-1101, 2016.

[20] H. S. Singh, G. K. Pandey, P. K. Bharti, M. K. Meshram, "A Compact Dual- Band Diversity Antenna for WLAN Applications with High Isolation," Microwave and optical technology letters, vol. 57, no. 4, pp. 906-912, 2015.

[21] Y. K. Mishra, S. P. Gangwar, "A Compact Rectangular Patch Antenna with Defected Ground Structure for Multiband Applications," Advances in VLSI, Communication, and Signal Processing, Springer, Singapore, vol. 587, pp. 229-239, 2020.

[22] P. Tajane and P. L. Zade, "Design and Implementation of Multiband Planar Antenna with DGS for Wireless Applications," in Optical and Wireless Technologies, Springer, Singapore, vol. 546, pp. 503-512, 2020.

[23] K. Suvarna, N. R. Murty, and D. V. Vardhan, "A Miniature Rectangular Patch Antenna Using Defected Ground Structure for WLAN Applications," Progress in Electromagnetics Research, vol. 95, pp. 131-140, 2019.

[24] S. Singh, G. Bharti, "A Multiband Antenna with Enhanced Bandwidth for Wireless Applications Using Defected Ground Structure," in Recent Trends in Communication, Computing, and Electronics, Springer, Singapore, vol. 524, pp. 95-101, 2019.

[25] D. Shashi Kumar and S. Suganthi, "Miniaturization of Microstrip Antenna with Enhanced Gain Using Defected Ground Structures," 2019 International Conference on Data Science and Communication (IconDSC), Bangalore, India, pp. 1-5, 2019. 